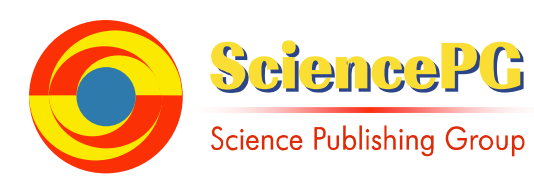

\title{
The balanced budget multiplier and labour intensity in home production
}

\author{
Masatoshi Yoshida ${ }^{1, *}$, Stephen J. Turnbull ${ }^{2}$ \\ ${ }^{1}$ Faculty of Economics, Ryukoku University, 67, Fukakusa, Tsukamoto-cho, Fushimi-ku, Kyoto, Japan \\ ${ }^{2}$ Graduate School of Systems and Information Engineering, University of Tsukuba, 1-1-1, Tennodai, Tsukuba, Ibaraki, Japan
}

Email address:

yoshida@econ.ryukoku.ac.jp (M. Yoshida)

\section{To cite this article:}

Masatoshi Yoshida, Stephen J. Turnbull. The Balanced Budget Multiplier and Labour Intensity in Home Production. International Journal of Economic Behavior and Organization. Special Issue: Recent Developments of Economic Theory and Its Applications.

Vol. 3, No. 2-1, 2015, pp. 23-30. doi: 10.11648/j.ijebo.s.2015030201.15

\begin{abstract}
This paper shows that the labour intensity of home production of a final consumption good affects national income and income multiplier effects of public expenditure financed by taxation. A reduction in labour intensity increases the level of national income but decreases the magnitude of the balanced budget multiplier effect. This result holds whether the tax instrument is distortionary or non-distortionary. It follows that the recent diffusion of labour-saving innovations such as washing machines and vacuum cleaners may have the effect of decreasing the effectiveness of fiscal policy.
\end{abstract}

Keywords: Multiplier Effects, Public Expenditure, Taxation, Labour Intensity, and Home Production

\section{Introduction}

In an imperfectly competitive economy, Dixon (1987), Mankiw (1988) and others showed that an expansion of public expenditure financed by lump-sum taxation gives rise to a positive income multiplier effect. However, Molana and Moutos (1991) pointed out that this effect depends on the type of taxation which the government uses to finance its expenditure and showed that (i) the multiplier effect is zero when taxes are proportional to total income (wage and profit income) and (ii) it can be negative when taxes are levied on wage income alone. After that, Heijdra, Ligthart, and van der Ploeg (1998) showed that result (i) depends on the assumption of the Cobb-Douglas utility function with unitary elasticity of substitution between leisure and consumption and demonstrated that when this elasticity is smaller (greater) than unity, the multiplier effect is positive (negative).

All of these income multiplier effects rely critically on how the household's labour supply to the market (market labour), which is the residual of leisure, responds to various types of taxation. However, following the theory of time allocation originated by Becker (1965), working time in home production (home labour) is another important factor affecting market labour. For example, not only inputs of intermediate goods but also assistance of home labour is necessary to produce elderly and child care at home; both gasoline and trip time as inputs are indispensable to travel by car. Therefore, it is important to explore how home production of a final consumption good needing labour as an input affects income multiplier effects of public expenditure.

This paper formulates a simple imperfectly competitive model with home production based on the following assumptions: (1) a Cobb-Douglas utility function consisting of leisure and a final consumption good; (2) a Leontief production function consisting of home labour and the composite intermediate good; (3) constant returns to scale technology under which a monopolistic firm produces its output with labour as the sole production factor. In this model, the marginal propensity to consume the composite good out of household income depends on labour intensity of home production, that is, the home labour-composite good ratio. A reduction in labour intensity significantly affects income multiplier effects of public expenditure, because it increases the household's demand for the composite good.

When public expenditure is financed by lump-sum taxation, a reduction in labour intensity increases the equilibrium level of national income. However, it decreases the magnitude of the multiplier effect. In the lump-sum tax system, as there is only the income effect, an increase in the lump-sum tax leads to a decrease in leisure which is a normal good. Since the final consumption good is also a normal good, home labour also decreases if it is required to produce this good. Thus, market labour and hence national income further increase. 
With distortionary income taxation, the income tax rate affects the marginal propensity to consume the composite good through the effect on the cost share of this good in home production. Therefore, together with labour intensity, this tax rate plays a critical role in determining the magnitude of the multiplier effect. The labour intensity effects on national income and the balanced budget multiplier also hold in the income tax system. This suggests that the diffusion of labour-saving innovations such as washing machines and vacuum cleaners may have the effect of decreasing the effectiveness of fiscal policy.

In the "comprehensive" income tax system, where tax rates on wage and profit income are the same, the multiplier effect is positive in the presence of home labour. With the Cobb-Douglas utility function, the income tax rate does not affect leisure since income and substitution effects cancel. Hence, without home labour, an increase in this tax rate for financing public expenditure does not change market labour and national income. However, a decrease in the final consumption good due to income taxation leads to a reduction in home labour. This identifies the channel for the positive multiplier effect in the household production economy.

This result may not hold when there is a "differential" income tax, i.e., the wage and profit income tax rates are different. However, even when government can not use a profit income tax at all as a policy instrument, the multiplier effect is positive if labour intensity is sufficiently high when the economy is operating on the upward sloping section of the Laffer curve. In this income tax system, leisure increases because the substitution effect dominates the income effect on leisure. However, since households substitute leisure for the final consumption good, home labour decreases. National income increases, as the decrease in home labour dominates the increase in leisure, implying an increase in market labour.

This paper is organized as follows. Section 2 presents an imperfectly competitive model with the home production. Section 3 studies how a change in labour intensity of home production affects national income and the balanced budget income multiplier effects of public expenditure. Finally, section 4 provides a brief conclusion.

\section{The Model}

First, let us describe the behaviour of the identical households. For simplicity, we normalize the number of households to unity. A representative household derives utility $u$ from pure leisure $X$ and a final consumption good $Z$. We assume the following Cobb-Douglas utility function:

$$
u=U(X, Z)=X^{1-\alpha} Z^{\alpha}
$$

Following Becker (1965), the final good is produced by using home labour $H$, and $I$ varieties of intermediate goods, $\mathbf{d} \equiv\left(d^{1}, \ldots, d^{i}, \ldots, d^{I}\right)$. We assume that technology of consumption is given by the following Leontief household production function:

$$
Z=\Gamma(\mathbf{d}, H)=\min \left(C / a^{C}, H / a^{H}\right)
$$

where $C$ is a CES-aggregation of $\mathbf{d}$ :

$$
C=\Theta(\mathbf{d})=I\left[(I)^{-1} \sum_{i=\mathbf{1}}^{I}\left(d^{i}\right)^{(\theta-\mathbf{1}) / \theta}\right]^{\theta /(\theta-\mathbf{1})} .
$$

The composite intermediate good $C$ and home labour $H$ are not substitutable. However, the different varieties are substitutable and the elasticity of substitution between them is given by the parameter $\theta(>1)$. Since the household efficiently produces the final consumption good, it follows from (2) that $C=a^{C} Z$ and $H=a^{H} Z$. Therefore, it holds that $H=r C$, where $r$ is the non-negative labour intensity in home production, i.e., $r \equiv H / C=a^{H} / a^{C} \geq 0$. The coefficients, $a^{C}$ and $a^{H}$, denote the input of the composite good and home labour, respectively, per unit of the final good.

The representative household has a time endowment of unity available for working, excluding pure leisure. This is allocated to home labour and market labour. Denoting labour supply to the market by $L$, the time constraint of the household is represented as $X+H+L=1$. We now choose the price of market labour, i.e., the wage, as the numeraire. Then, the household budget is given by $\mathbf{p}^{\prime} \mathbf{d}=(1-t) L+(1-\tau) \Pi-T$, where $\mathbf{p} \equiv\left(p^{1}, \ldots, p^{i}, \ldots, p^{I}\right)$ is the price vector of the intermediate goods, $\Pi$ is profit income distributed to the household, $t$ and $\tau$ are taxes on wage and profit income, respectively, and $T$ is a lump-sum tax.

The utility maximization problem for the representative household can be solved as follows. Given levels of $C$ and $\mathbf{p}$, the household minimizes its expenditure $\mathbf{p}^{\prime} \mathbf{d}$. The optimal solutions for $d^{i}(i=1, \ldots, I)$ are given by $d^{i}=\left(p^{i} / P\right)^{-\theta} C$, where $P$ is the consumer price index for C:

$$
P=I^{-1}\left[I^{-\theta} \sum_{i=1}^{I}\left(p^{i}\right)^{1-\theta}\right]^{1 /(1-\theta)}
$$

and it holds that $\min \mathbf{p}^{\prime} \mathbf{d}=P C$. Using this and the time constraint, the household budget becomes $P C+(1-t)(H+X)=F$, where $F$ is full-employment disposable income, i.e., $F \equiv 1-t+(1-\tau) \Pi-T$. Now, using $C=a^{C} Z$ and $H=a^{H} Z$, this budget can be rewritten as

$$
(1-t) X+Q Z=F
$$

where $Q$ is the shadow price of the final consumption good and is computed as $Q=P a^{C}+(1-t) a^{H}$. The household maximizes the Cobb-Douglas utility function given by (1) with respect to $X$ and $Z$ subject to the household budget

\footnotetext{
${ }^{1}$ The government can tax consumption of households as well as wage and profit income. However, any one of these tax instruments is redundant. Therefore, without loss of generality, we set the consumption tax rate to be zero in this paper.
} 
(5). We obtain the optimal solutions for pure leisure and the final consumption good as follows: $X=(1-\alpha) F /(1-t)$ and $Z=\alpha F / Q$.

The optimal level of the composite intermediate good is given by

$$
C=a^{C} Z=\frac{c F}{P}
$$

where $c$ is the marginal propensity to consume the composite good out of full-employment disposable income. The marginal propensity to consume depends on the labour intensity, since we can rewrite $c$ as $c=s \alpha$, where $s$ is the cost share of the composite good in household production, i.e., $s \equiv P C / Q Z=P /[P+(1-t) r]$. Differentiating $C$ in (6) with respect to $r$, we obtain

$$
C_{r} \equiv \frac{\partial C}{\partial r}=\frac{c_{r} F}{P}<0, \text { where } c_{r}=-\frac{(1-t) \alpha P}{[P+(1-t) r]^{2}}<0 .
$$

Therefore, a reduction in the labour intensity increases the household's demand for the composite intermediate good. ${ }^{2}$

Second, let us formulate the government sector. The government imposes lump-sum and income taxes on households to purchase $I$ varieties of the intermediate goods, $\mathbf{g} \equiv\left(g^{1}, \ldots, g^{i}, \ldots, g^{I}\right)$. The government's budget is given by $\mathbf{p}^{\prime} \mathbf{g}=t L+\tau \Pi+T$. For simplicity, we assume that the CES-aggregation of $\mathbf{g}$ is the same as that of $\mathbf{d} .^{3}$

Then, it follows from (3) that $G=\Theta(\mathbf{g})$, where $G$ is the composite intermediate good. Given levels of $G$ and $\mathbf{p}$, the government minimizes its expenditure $\mathbf{p}^{\prime} \mathbf{g}$ with respect to g subject to this constraint. The optimal solutions for $g^{i}$ $(i=1, \ldots, I)$ are given by $g^{i}=\left(p^{i} / P\right)^{-\theta} G$. Using $\min \mathbf{p}^{\prime} \mathbf{g}=P G$, the government's budget constraint can be rewritten as

$$
P G=t L+\tau \Pi+T
$$

Given the level of $G$, the government must determine each of three tax variables $(T, t, \tau)$ so as to satisfy this budget constraint.

Third, the production sector of the model is formulated as follows. Every intermediate good is produced by a single firm, so that there are $I$ firms. We assume that the number of firms is so large that the behaviour of an individual firm can not influence macroeconomic variables, i.e., $P, C$, and $G$

\footnotetext{
${ }^{2}$ A reduction in the labour intensity increases the household's market labour, because it follows from $X_{r}=0, H_{r}=\alpha F P /[P+(1-t) r]^{2}>0$, and $X_{r}+H_{r}+L_{r}=0$ that $L_{r}=-H_{r}<0$.

${ }^{3}$ Under this assumption, because the private and public demand functions for output of a monopolistic firm have the same price elasticity $\theta$, the aggregate price elasticity of demand is not affected by the composition of aggregate demand.
}

Under constant returns to scale technology, firm $i$ produces its output $y^{i}$ with labour $l^{i}$ as the sole production factor. The production functions of all firms are assumed to be the same. They are given by $y^{i}=l^{i} / \varphi$, where $\varphi(>0)$ is the constant marginal cost in terms of units of labour. The common wage rate is paid by firms because labour is mobile across firms. Under the Cournot assumption that the other firms do not change their output levels, firm $i$ maximizes its profit, $\pi^{i}=\left(p^{i}-\varphi\right) y^{i}$, with respect to output $y^{i}$ subject to the inverse demand function, $p^{i}=\left[y^{i} /(C+G)\right]^{-1 / \theta} P .{ }^{4}$ As a result, marginal revenue should equal marginal cost. The profit maximization condition is given by $p^{i}=p \equiv \mu \varphi$, where $\mu \equiv \theta /(\theta-1)>1$, that is, $\mu$ is price mark-up on variable labor cost. It follows from (4) and $p^{i}=p$ for all $i$ that $P=p=\mu \varphi$. Thus, the price index $P$ is constant.

Finally, an imperfectly competitive equilibrium is described. We restrict our attention to a symmetrical equilibrium, where the following conditions are satisfied: $d^{i}=d, g^{i}=g$, and $y^{i}=y$. In this equilibrium, it holds that $C=I d$ and $G=I g$. Defining national income (aggregate output) by $Y \equiv \sum_{i} p^{i} y^{i} / P$, we obtain $Y=I y$. Aggregate profit $\Pi \equiv \sum_{i} \pi^{i}$ can be represented as a linear function of national income, i.e., $\Pi=\theta^{-1} P Y$. The symmetrical equilibrium conditions are shown by the following simultaneous equations which have national income $Y$ and any one of government's policy instruments $(T, t, \tau, G)$ as unknown variables: ${ }^{5}$

$$
\begin{gathered}
Y=c\left[(1-t) P^{-1}+(1-\tau) \theta^{-1} Y-P^{-1} T\right]+G, \\
G=\left[t+(\tau-t) \theta^{-1}\right] Y+P^{-1} T
\end{gathered}
$$

Eqs. (9) and (10) are the goods-market equilibrium condition in aggregate form and the government's budget constraint in terms of national income, respectively. ${ }^{6}$

\section{Labour Intensity and the Balanced Budget Multiplier}

In this section, we study how a change in the labour intensity of home production of the final consumption good affects an equilibrium level of national income and the balanced budget income multiplier effects of public expenditure financed by various types of taxation. The two ways for financing public expenditure are considered: lump-sum taxation and income taxation. Irrespective of these

\footnotetext{
${ }^{4}$ The inverse demand function of firm $i$ can be obtained by eliminating $d^{i}$ and $g^{i}$ from $d^{i}=\left(p^{i} / P\right)^{-\theta} C, g^{i}=\left(p^{i} / P\right)^{-\theta} G$, and $d^{i}+g^{i}=y^{i}$.

${ }^{5}$ We need not consider the labour-market equilibrium condition in the following analyses due to Walras's law.

${ }^{6}$ We can derive (10) by using the government's budget constraint (8) and the identity in national income account, i.e., $P Y=L+\Pi$.
} 
financing ways, it will be shown that a reduction in labour intensity increases the level of national income but decreases the magnitude of the balanced budget multiplier effect.

\subsection{Lump-Sum Taxation}

Under this tax system, the goods-market equilibrium condition (9) and the government's budget constraint (10) become

$$
\begin{gathered}
Y=c\left(P^{-1}+\theta^{-1} Y-P^{-1} T\right)+G, \\
G=P^{-1} T,
\end{gathered}
$$

respectively, where $c=\alpha P /(P+r)$. Eliminating $T$ from (11) and (12), we obtain the equilibrium level $\hat{Y}$ of national income:

$$
\hat{Y}=\frac{c\left(P^{-1}-G\right)+G}{1-\theta^{-1} c}>0,
$$

where $0<1-\theta^{-1} c<1$ and $P^{-1}-G=P^{-1}(1-T)>0$. Thus, we assume that $T<1$, that is, the lump-sum tax does not consume all of full income.

Differentiating $\hat{Y}$ in (13) with respect to $r$, we have

$$
\hat{Y}_{r}=\frac{c_{r}\left(P^{-1}-G+\theta^{-1} G\right)}{\left(1-\theta^{-1} c\right)^{2}}<0 .
$$

Noting that $c_{r}<0$ in (7), we find that $\hat{Y}_{r}$ is negative. Therefore, for a given level of public expenditure, a reduction in the labour intensity increases the equilibrium level of national income. This is because the household's demand for the composite intermediate good is stimulated. From (13), we also have

$$
\hat{Y}_{G}=\frac{1-c}{1-\theta^{-1} c}>0
$$

This is the well known result in an imperfectly competitive economy that the income multiplier effect of public expenditure due to the increase in profit is positive.

Now, differentiating $\hat{Y}_{G}$ with respect to $r$ and using $c_{r}<0$, we obtain

$$
\frac{\partial \hat{Y}_{G}}{\partial r}=-\frac{c_{r}\left(1-\theta^{-1}\right)}{\left(1-\theta^{-1} c\right)^{2}}>0 .
$$

Thus, a reduction in the labour intensity decreases the magnitude of the multiplier effect. ${ }^{7}$ We can intuitively explain this result as follows. Since there is now only the income effect, an increase in the lump-sum tax for financing public expenditure leads to a decrease in leisure which is a normal

\footnotetext{
${ }^{7}$ Note that this implies that the effect in the model with home labour (i.e., $r>0$ ) is greater than that in the traditional model without it (i.e., $r=0$ ).
}

good. The final consumption good is also a normal good. Therefore, if home labour is required to produce this good, market labour and national income further increase since home labour as well as leisure decreases.

\subsection{Income Taxation}

Under the income tax system, the goods-market equilibrium condition (9) and the government's budget constraint (10) become

$$
\begin{gathered}
Y=c\left[(1-t) P^{-1}+(1-\tau) \theta^{-1} Y\right]+G, \\
G=\left[t+(\tau-t) \theta^{-1}\right] Y,
\end{gathered}
$$

respectively. Note that the marginal propensity of consumption $c$ depends on the wage tax rate $t$ as well as the labour intensity $r$. Given levels of $Y$ and $G$, the government must determine two tax rates, $t$ and $\tau$, so as to satisfy (15). Eliminating $G$ from (14) and (15), we obtain

$$
Y=\frac{c(1-t) P^{-1}}{1-t+(t-\tau) \theta^{-1}-(1-\tau) \theta^{-1}} .
$$

For a given level of public expenditure, together with (15), (16) determines national income $Y$ and the wage tax rate $t$ in the symmetrical equilibrium.

In this paper, we treat the wage tax rate $t$ as an endogenous variable and analyze the two polar cases with respect to the profit tax rate $\tau$. In the one case, the government equalizes the profit tax rate to the wage tax. We call this the comprehensive income tax system. In the other, the government sets the profit tax rate to zero. We call this the differential income tax system.

\section{(1) The Comprehensive Income Tax System}

Since $\tau=t$ in this tax system, (15) and (16) become

$$
\begin{gathered}
G=t Y, \\
Y=\frac{c P^{-1}}{1-\theta^{-1} c},
\end{gathered}
$$

respectively. The set of the income tax rate and national income which satisfy (17) is shown by the hyperbola $G B C$ in Fig. 1. On the other hand, it follows from (18) that

$$
Y_{t}=\frac{c_{t} P^{-1}}{\left(1-\theta^{-1} c\right)^{2}} \geq 0, \text { where } c_{t}=-\frac{\alpha \operatorname{Pr}}{[P+(1-t) r]^{2}} \geq 0
$$

Thus, if the labour intensity is positive, i.e., $r>0$, a set of the income tax rate and national income which satisfy (18) is shown by the upward sloping curve GME. This curve intersects the horizontal line, i.e., $Y=\bar{Y}$, at the point $(1, \bar{Y})$, where $\bar{Y} \equiv \alpha / P\left(1-\alpha \theta^{-1}\right)>0$. Note that this horizontal line is the GME in the case of $r=0$. 


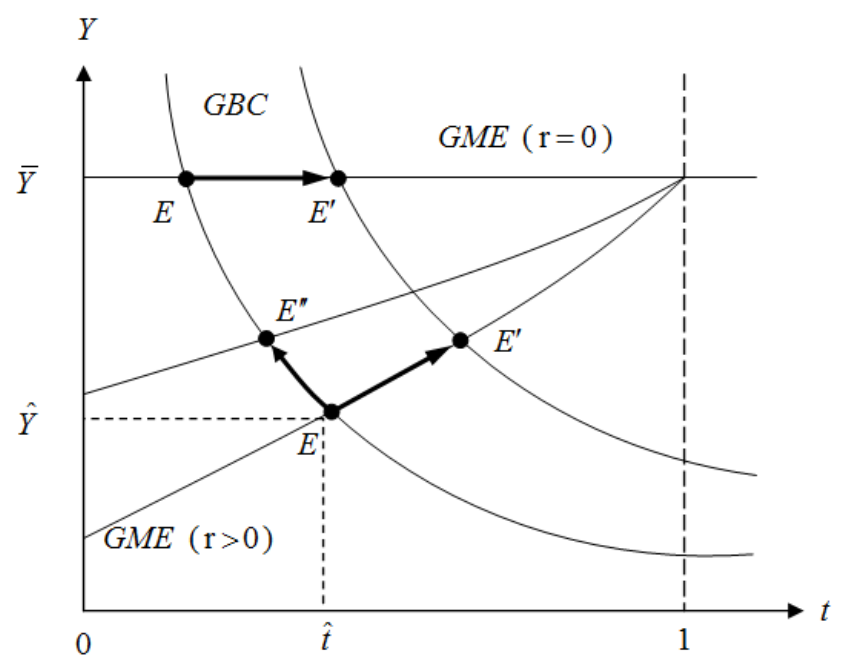

Fig. 1. The multiplier effect under the comprehensive income tax system.

The intersection point $E$ of the hyperbola $G B C$ and the curve $G M E$ is the unique equilibrium point. The tax rate and national income in the equilibrium are given by

$$
\hat{t}=\frac{\left[\left(1-\alpha \theta^{-1}\right) P+r\right] G}{r G+\alpha} \text { and } \hat{Y}=\frac{r G+\alpha}{\left(1-\alpha \theta^{-1}\right) P+r},
$$

respectively. Differentiating $\hat{Y}$ with respect to $r$, we obtain

$$
\hat{Y}_{r}=\frac{(G-\bar{Y}) P\left(1-\alpha \theta^{-1}\right)}{\left[\left(1-\alpha \theta^{-1}\right) P+r\right]^{2}}<0,
$$

where $G<\hat{Y} \leq \bar{Y}=\alpha / P\left(1-\alpha \theta^{-1}\right)$. Thus, a reduction in the labour intensity increases the equilibrium level of national income. ${ }^{8}$ This implies that the equilibrium national income with home labour is smaller than that without it.

A rise in public expenditure $G$ shifts the hyperbola $G B C$ upward. However, the curve GME does not shift. The equilibrium point moves from $E$ to $E^{\prime}$ (see Fig.1). Since $\hat{Y}=\bar{Y}$ in the case of $r=0$, national income is not affected by public expenditure. However, national income increases in the case of $r>0$. Totally differentiating (17) and (18) at a neighborhood of the equilibrium point to verify mathematically this result, we obtain

$$
\begin{gathered}
d Y+(Y / t) d t=(1 / t) d G \\
\left(-1 / Y_{t}\right) d Y+d t=0
\end{gathered}
$$

where $Y_{t}>0$. Since it holds that

\footnotetext{
${ }^{8}$ This result can be geometrically confirmed in Fig.1. It follows from (19) and $c_{r}<0$ that $Y_{r}<0$. Therefore, for a given level of public expenditure, since a decrease in $r$ shifts the curve GME upward, the equilibrium point moves from $E$ to $E^{\prime \prime}$, so that national income increases.
}

$$
\begin{aligned}
& \hat{Y}_{G}=\frac{1}{t J}=\frac{r}{\left(1-\theta^{-1} \alpha\right) P+r}>0 \text { and } \\
& \hat{t}_{G}=\frac{1}{t J Y_{t}}=\frac{\alpha\left[\left(1-\theta^{-1} \alpha\right) P+r\right]}{(r G+\alpha)^{2}}>0,
\end{aligned}
$$

where $J=1+\left(Y / t Y_{t}\right)>0$, we can confirm an increase in national income.

Differentiating $\hat{Y}_{G}$ with respect to $r$, we obtain

$$
\frac{\partial \hat{Y}_{G}}{\partial r}=\frac{\left(1-\theta^{-1} \alpha\right) P}{\left[\left(1-\theta^{-1} \alpha\right) P+r\right]^{2}}>0 .
$$

Thus, the magnitude of the multiplier effect decreases with a reduction in the labour intensity. ${ }^{9}$ Note that the multiplier effect is positive with home labour, but this effect is zero without it. We can explain the intuition behind these results. As was pointed out by Heijdra, Lighthart and van der Ploeg (1998), with the Cobb-Douglas utility function the income tax rate does not affect leisure, since income and substitution effects in leisure cancel due to the unitary elasticity between leisure and the final consumption good. Hence, without home labour, an increase in this tax rate for financing public expenditure does not change market labour and national income. However, a decrease in the final good due to income taxation leads to a reduction in home labour. This identifies the channel for the positive multiplier effect in the household production economy.

\section{(2) The Differential Income Tax System}

Since the profit tax rate is zero in this system, the government's budget constraint (15) and the goods-market equilibrium condition (16) become

$$
\begin{array}{r}
G=\left(1-\theta^{-1}\right) t Y, \\
Y=\frac{(1-t) c P^{-1}}{1-\theta^{-1} c-t\left(1-\theta^{-1}\right)},
\end{array}
$$

respectively. The set of the wage tax rate and national income which satisfy (19) is shown by the downward sloping curve. Differentiating (20) with respect to $t$, we have

$$
Y_{t}=\frac{c_{t}(1-t)\left[1-t\left(1-\theta^{-1}\right)\right]-c(1-c) \theta^{-1}}{P\left[1-\theta^{-1} c-t\left(1-\theta^{-1}\right)\right]^{2}} .
$$

Although the second term in the numerator of the right-hand side on (21) is negative, the first term is not so. Therefore, since the sign of $Y_{t}$ is indeterminate, the configuration of the curve $G M E$ is ambiguous in general.

\footnotetext{
${ }^{9}$ Geometrically, this result can be explained as follows. In Fig.1, since the tangent of the GME curve is steep when the labour intensity is high, the upward shift of the $G B C$ curve due to an increase in public expenditure produces the great expansion effect on the equilibrium national income.
} 
In the case of $r=0$, it follows from (21) and $c_{t}=0$ that $Y_{t}<0$. Thus, without home labour, as is illustrated in Fig.2, the curve GME is downward sloping. For a given level of $G$, it should be now noted that there are two equilibrium points. ${ }^{10}$ As $G$ increases, the one point moves on the line $G M E$, increasing $t$ but decreasing $Y$. See the movement of the equilibrium point from $E$ to $E^{\prime}$ in Fig.2. This movement arises in the upward section of the Laffer curve. ${ }^{11}$ Thus, a rise in public expenditure decreases national income. From (20) and $c_{r}<0$, we also have

$$
Y_{r}=\frac{c_{r}(1-t)\left[1-t\left(1-\theta^{-1}\right)\right]}{P\left[1-\theta^{-1} c-t\left(1-\theta^{-1}\right)\right]^{2}}<0 .
$$

In Fig.2, this implies that a rise in $r$ shifts the curve $G M E$ downward. Therefore, for a given level of public expenditure, an increase in the labour intensity decreases the equilibrium level of national income. The same result holds in the case of $r>0$, too.

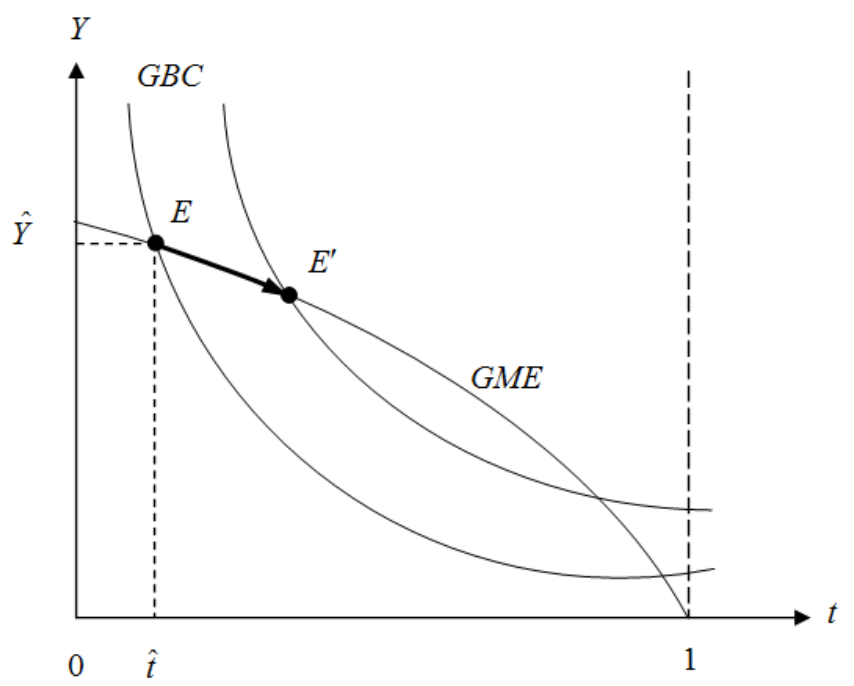

Fig. 2. The multiplier effect under the differential income tax system without home labour (i.e., $\mathrm{r}=0$ ).

On the other hand, if $r>0$, the first term in the numerator of the right-hand side on (21) is positive. Since it holds that $Y_{t}<0$ at a neighborhood of $t=1$, the curve $G M E$ is downward sloping. However, noting that at $t=0,(21)$ can be rewritten as

$$
Y_{t}=\frac{r\left(1-\theta^{-1}\right)-\theta^{-1} P(1-\alpha)}{P c^{-1}(P+r)\left(1-\theta^{-1} c\right)^{2}}
$$

the curve GME may be upward sloping at a neighborhood of $t=0$. If a positive value of the labour intensity is sufficiently

\footnotetext{
${ }^{10}$ In the differential income tax system, the income tax rate and national income in the equilibrium cannot be explicitly solved as functions of public expenditure. ${ }^{11}$ Note that the other equilibrium point moves in the opposite direction on the line GME in Fig. 2. This movement arises in the downward section of the Laffer curve.
}

great, i.e., $r>P(1-\alpha) /(\theta-1)$, the first term in the numerator of the right-hand side on (22) is dominant. Thus, it holds that $Y_{t}>0$ for low tax rates. If the economy is operating on the upward sloping section of the Laffer curve (see Fig.3), then a rise in public expenditure increases national income.

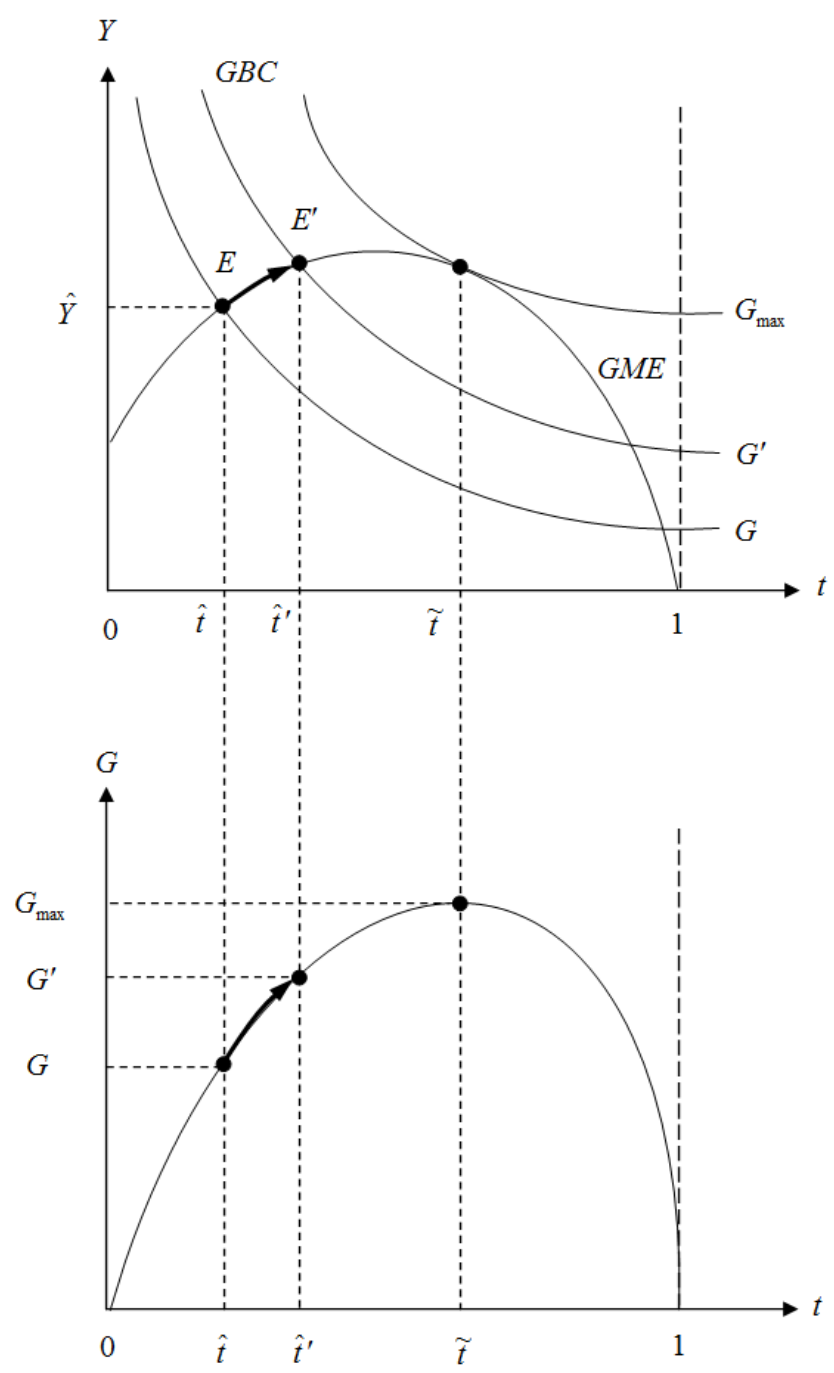

Fig. 3. The multiplier effect under the differential income tax system with home labour (i.e., $\mathrm{r}>0$ ) and the Laffer curve.

In order to verify the above geometrical results, totally differentiating (19) and (20) at a neighborhood of the equilibrium point, we obtain

$$
\begin{gathered}
d Y+(Y / t) d t=\left[1 /\left(1-\theta^{-1}\right) t\right] d G, \\
\left(-1 / Y_{t}\right) d Y+d t=0 .
\end{gathered}
$$

From these equations, we have

$$
\hat{Y}_{G}=\frac{1}{\left(1-\theta^{-1}\right) t K} \text { and } \hat{t}_{G}=\frac{1}{\left(1-\theta^{-1}\right) t K Y_{t}},
$$

where $K \equiv 1+\left(Y / t Y_{t}\right)$. If the economy is operating on the upward sloping section of the Laffer curve, it follows from 
$\hat{t}_{G}>0$ that $K Y_{t}>0$. It holds that $Y_{t}<0$ in the case of $r=0$. Since $K<0$, we can derive $\hat{Y}_{G}<0$. But, as has been already mentioned, if the sign of $r$ is positive and its value is sufficiently great, it is possible that $Y_{t}>0$ at a neighborhood of $t=0$. In this case, it follows from $K>0$ that $\hat{Y}_{G}>0$.

In the differential income tax system, with home labour it is possible that the multiplier effect is positive, while without it this effect is negative. The intuition behind these results can be explained as follows. Because taxes are imposed on only part of household income, the tax rate in this tax system must be increased by more than in the comprehensive tax system, in order to maintain a balanced budget. Since the positive substitution effect dominates the negative income effect in leisure, the wage tax rate increases leisure. Thus, in the Molana and Moutos (1991) model without home labour, an increase in this tax rate decreases market labour and national income. However, as a rise in the wage tax rate induces households to substitute leisure for the final consumption good, this good and thus home labour decrease in the household production economy with home labour. When the labour intensity is sufficiently great, a decrease in home labour may dominate an increase in leisure, so that market labour and national income will increase.

\section{Conclusion}

The objective of this paper has been to study how home production of a final consumption good needing inputs of labour as well as intermediate goods affects income multiplier effects of public expenditure financed by of taxation in an imperfectly competitive model. In this model, labour intensity of home production significantly influences the marginal propensity to consume the composite good out of household income. Therefore, labour intensity plays an important role in determining the magnitude and the sign of the income multiplier effect.

We have shown that (i) a reduction in labour intensity increases the level of national income but decreases the magnitude of the balanced budget multiplier effect; (ii) this result holds whether the tax instrument is distortionary or non-distortionary; (iii) in the "lump-sum" tax system, the multiplier effect in the traditional model without home labour is smaller than that with it; (iv) in the "comprehensive" income tax system, the effect is positive in the presence of home labour; (v) in the "differential" income tax system, if labour intensity is sufficiently high, the effect is positive when the economy is operating on the upward sloping section of the Laffer curve.

Here it may be helpful to comment on the assumptions which were used in deriving these results. First, the home production function has been assumed to be of the Leontief type. This is the standard approach to applying the Becker (1965) framework, since it is flexible enough to include as a special case the pure market labor-leisure tradeoff, while being tractable when used as a component of a larger model. This function is frequently used, for example by Kleven (2004) in a study of the optimal commodity tax rule with home production.

Second, we have assumed a Cobb-Douglas utility function. The Cobb-Douglas function is important since it isolates the channel for the income multiplier effect via cost reduction in home production from the effects of non-unitary elasticity of substitution identified by Heijdra, Lighthart and van der Ploeg (1998). Dixon (1987) assumed a Cobb-Douglas function which depends on money balances as well as leisure and consumption. This would add little to our model so we follow Mankiw (1988) in excluding money from the utility function.

Third, we have assumed that public expenditure is not useful. This is a standard approach which allows us to focus solely on the transmission mechanism for fiscal policy. However, it is important to note that if the public good provided contributes to reduction of the cost of home production, there will be effects on the channel discussed in this paper. In a companion paper, Yoshida and Turnbull (2009), we characterize the optimal provision of such a public good. Integrating the fiscal and public good provision aspects of public expenditure is beyond the scope of this paper, and we leave it as a task for future research.

Finally, we have not considered the possible effects on saving, since that would require a dynamic model. In that case, an additional independent instrument (the consumption tax) would be available. We consider extension to a dynamic model to be an important task for future research in this area.

\section{Acknowledgement}

The authors would like to thank Professors A. Yakita and S. Kaku for constructive comments. The first author acknowledges the financial support from the Ministry of Education, Culture, Sports, Science and Technology of Japan under Grants-in-Aid for Scientific Research C (No.18530227). The paper is dedicated to Professor Toshikazu Ito on the occasion of his retirement at Ryukoku University.

\section{References}

[1] Becker, G. S. (1965) . 'A Theory of the Allocation of Time', Economic Journal, 75, 493-517.

[2] Dixon, H. D. (1987). 'A Simple Model of Imperfect Competition with Walrasian Features', Oxford Economic Papers, 39, 134-160.

[3] Heijdra, B. J., Lighthart, J. E. and van der Ploeg, F. (1998). 'Fiscal Policy, Distortionary Taxation, and Direct Crowding Out under Monopolistic Competition', Oxford Economic Papers, 50, pp.79-88.

[4] Kleven, H. J. (2004). 'Optimal Taxation and the Allocation of Time', Journal of Public Economics, 88, pp. 545-557.

[5] Mankiw, N. G. (1988). 'Imperfect Competition and the Keynesian Cross', Economics Letters, 26, pp. 7-13. 
[6] Molona, H. and Moutos, T. (1991). 'A Note on Taxation, Imperfect Competition and the Balanced Budget Multiplier', Oxford Economic Papers, 43, pp.68-74.
[7] Yoshida, M. and Turnbull, S. (2009). 'Public Goods and the Technology of Consumption under Imperfect Competition', mimeo. 